\title{
Morfologi Ginjal Anjing Kintamani Betina
}

\section{(KIDNEY MORPHOLOGY OF FEMALE KINTAMANI DOG)}

\author{
I Kadek Pradhana Putra ${ }^{1 *}$, Luh Gde Sri Surya Heryani ${ }^{1}$, Ni Luh Eka Setiasih ${ }^{2}$ \\ ${ }^{1}$ Laboratorium Anatomi Veteriner, Fakultas Kedokteran Hewan, Universitas Udayana Jln. \\ PB. Sudirman Denpasar Bali. \\ ${ }^{3}$ Laboratorium Histologi Veteriner, Fakultas Kedokteran Hewan, Universitas Udayana, Jln. \\ PB. Sudirman Denpasar Bali. \\ *Email: ikadekpradhanapura01@gmai.com
}

\begin{abstract}
Abstrak
Anjing kintamani adalah anjing lokal jenis pegunungan yang hidup di sekitar Desa Sukawana, Kecamatan Kintamani, Kabupaten Bangli, Bali. Penelitian mengenai sistem urinaria pada anjing kintamani belum pernah dilakukan. Peneltian ini bertujuan untuk mengetahui morfologi anatomi dan morfometrik ginjal (ren) anjing kintamani secara makroskopik dan mikroskopik. Penelitian ini menggunakan ginjal dari lima ekor anjing kintamani dengan umur rata-rata 1-2 tahun yang berasal dari desa Sukawana. Pemeriksaan histologi menggunakan metode Kiernan dan pewarnaan Hematoksilin-eosin (HE). Data pengukuran berat, panjang, lebar dan tebal ginjal dianalisis menggunakan Independent Sample T-test untuk membandingkan ginjal kanan dan kiri. Sedangkan, struktur anatomi dan histologi ginjal dianalisis secara deskriptif kualitatif. Hasil penelitian menunjukkan berat ginjal kanan dan kiri berbeda nyata sedangkan panjang, lebar dan tebal tidak berbeda nyata. Hasil rata-rata pengukuran morfometri ginjal kanan, berat: 19,39 $\pm 4,24$ g; panjang: $50,19 \pm 2,43 \mathrm{~mm}$; lebar: $29,57 \pm 1,94 \mathrm{~mm}$; tebal kortek: $6,17 \pm 0,45 \mathrm{~mm}$; tebal medulla: $8,48 \pm 0,56$ $\mathrm{mm}$ dan tebal pelvis: $8,11 \pm 1,29 \mathrm{~mm}$. Sedangkan ginjal kiri, berat: $20,51 \pm 4,20 \mathrm{~g}$; panjang: $50,88 \pm$ 2,38 mm; lebar: $29,40 \pm 1,65 \mathrm{~mm}$; tebal kortek: $6,17 \pm 0,31 \mathrm{~mm}$; tebal medulla: $8,50 \pm 0,49 \mathrm{~mm}$ dan tebal pelvis: $8,95 \pm 2,08 \mathrm{~mm}$. Hasil pengukuran histomorfometri ginjal, tebal kapsula 37,18 $\pm 5,67$ $\mu \mathrm{m}$; luas glomelurus $8.598,34 \pm 1.277,06 \mu \mathrm{m}$; tebal korteks 3.798,34 $\pm 603,54 \mu \mathrm{m}$ dan tebal medula $1.485,09 \pm 286,92 \mu \mathrm{m}$.
\end{abstract}

Kata kunci: Anjing kintamani; ginjal; morfometri; histomorfometri.

\begin{abstract}
Kintamani dog is a local mountain type dog that lives in Sukawana Village, Kintamani District, Bangli Regency, Bali. Research on the urinary system in Kintamani dog has never been done. This study aims to determine the morphology of anatomy and morphometrics of the kidney (ren) in Kintamani dog macroscopically and microscopically. This study used the kidney of 5 Kintamani dogs with an average age of 1-2 years old originating from the village of Sukawana. Histological observation based on Kiernan method and Hematoxylin-eosin (HE) staining. Weight measurement data, length, width, and renal thickness data were analyzed using Independent Sample T-test to compare the left and right kidney. Meanwhile, the anatomical and histological structure of the kidneys were analyzed descriptively qualitatively. The results showed that the left and right kidney weight was significantly different $(\mathrm{P}<0.05)$, while the length, width, and thickness were not significantly different $(\mathrm{P}>0.05)$. Measurements of right renal morphometry, weight: $19.39 \pm 4.24 \mathrm{~g}$; length: 50.19 $\pm 2,43 \mathrm{~mm}$; width: $29.57 \pm 1.94 \mathrm{~mm}$; cortex thickness: $6.17 \pm 0.45 \mathrm{~mm}$; medulla thickness: $8.48 \pm$ $0.56 \mathrm{~mm}$ and pelvis thickness: $8.11 \pm 1.29 \mathrm{~mm}$. While the left kidney, weight: $20.51 \pm 4.20 \mathrm{~g}$; length: $50.88 \pm 2,38 \mathrm{~mm}$; width: $29.40 \pm 1.65 \mathrm{~mm}$; cortex thickness: $6.17 \pm 0.31 \mathrm{~mm}$; medulla thickness: 8.50 $\pm 0.49 \mathrm{~mm}$ and pelvis thickness: $8.95 \pm 2.08 \mathrm{~mm}$. Results of renal histomorphometry measurements, capsula thickness: $37.18 \pm 5,67 \mu \mathrm{m}$; glomerulus area: 8.598,34 $\pm 1.277,06 \mu \mathrm{m}$; cortex thickness: $3.798,34 \pm 603,54 \mu \mathrm{m}$ and medulla thickness: $1.485,09 \pm 286,92 \mu \mathrm{m}$.
\end{abstract}

Keywords: Kintamani dog; kidney; morphometry; histomorphometry. 


\section{PENDAHULUAN}

Anjing kintamani adalah sebutan kelompok anjing lokal jenis pegunungan yang hidup di sekitar Desa Sukawana, Kecamatan Kintamani, Kabupaten Bangli, Bali. Anjing lokal jenis pegunungan ini memiliki penampilan yang sangat indah dan cantik yang berbeda dengan anjing geladak yang ada di Bali (Puja, 2007). Anjing Kintamani dikenal sebagai anjing pintar, berani, kuat, dan loyal kepada pemiliknya (Puja et al., 2005).

Sistem urinari merupakan salah satu bagian dari hewan yang sangat berperan dalam menjaga kesehatan. Sistem urinari memiliki tiga fungsi, yaitu metabolisme, hormonal dan ekskresi. Sistem ini terdiri dari dua bagian, yaitu sistem urinari bagian atas dan bawah. Sistem urinari bagian atas hanya terdiri dari ginjal sedangkan sistem urinari bagian bawah disusun oleh ureter, vesica urinaria dan urethra.

Pada sistem urinari, Ginjal kanan terletak pada bagian ventral sampai bagian dorsal dari dua atau tiga tulang rusuk terakhir dan prosesesus transversal lumbar pertama (Evans., 1993). Ginjal kiri biasanya lebih panjang dan letaknya lebih dekat ke bidang median dan memanjang ke kaudal. Ginjal kiri biasanya terletak pada bagian ventral tulang rusuk terakhir dan dua atau tiga prosesus transversus lumbar pertama (Evans, 1993). Ginjal memiliki peran yang sangat penting karena ia memiliki dua fungsi utama, yaitu filtrasi dan reabsorpsi. Selain itu, ginjal juga memiliki peran penting dalam sistem sirkulasi darah. Ginjal turut berperan dalam proses pembentukan sel darah merah dan menjaga tekanan darah. Sama halnya pada manusia, hewan juga dapat mengalami gangguan pada sistem urinarinya. Gangguan tersebut dapat terjadi pada sistem urinari bagian bawah, bagian atas, maupun keduanya (Ramdhany, 2009).

Sampai saat ini penelitian tentang karakteristik sistem urinari pada anjing kintamani masih belum pernah dilakukan, walaupun penelitian ini sangat penting bila dikaitkan dengan kepentingan klinis maupun preklinis. Beberapa penelitian terdahulu mengenai ginjal telah dilakukan pada hewan lain yaitu mengenai anatomitopografi dan morfometri ginjal normal pada kelinci (Dimitrov et al., 2012), dan penyakit ginjal kronis pada kucing (Yanuartono et al., 2017), oleh karena itu perlu kiranya dilakukan penelitian khususnya mengenai karakteristik anatomi dan morfometrik ginjal pada anjing kintamani yang nantinya dapat dipakai sebagai acuan untuk kepentingan diagnostik.

\section{METODE PENELITIAN}

\section{Sampel penelitian}

Penelitian ini menggunakan sampel berupa ginjal dari anjing kintamani Bali. Sampel diambil dari anjing kintamani pada saat program eliminasi (depopulasi) di Desa Sukawana. Sampel diambil dari lima ekor anjing kintamani betina.

\section{Variabel penelitian}

Variabel pada penelitian ini adalah: mengamati morfologi dan morfometri anatomi ginjal meliputi berat dari ginjal dan ketebalan kortek, medula, dan pelvis renalia. Mengamati morfologi histologi ginjal yang meliputi kapsula, kortek, dan medula. Histomorfometri yang meliputi ketebalan kapsula, ketebalan kortek, ketebalan medula, dan luas glomerulus.

\section{Pengambilan sampel}

Pengambilan sampel dilakukan di Desa Sukawana pada saat eliminasi. Kemudian anjing dieutanasia, dan dilakukan pembedahan abdomen untuk pengambil sampel berupa ginjal. Dilakukan pengukuran ginjal secara anatomi dan sampel disimpan dalam NFB $10 \%$.

\section{Pembuatan preparat histologi}

Sampel ginjal yang telah diambil dicuci dengan cairan fisiologis $0,9 \%$ dan dimasukkan kedalam larutan formaldehid 10\%. Pembuatan sedian histologi dilakukan mengacu pada metode yang digunakan oleh Luna (1968). Langkah 
langkah yang dilakukan: jaringan yang telah difiksasi dalam formalin $10 \%$ selama 24 jam, diiris (trimming) agar dapat dimasukkan ke dalam kotak untuk di proses ke dalam tuissue processor. Kemudian jaringan tersebut dimasukkan ke dalam alkohol 70\%, alkohol $80 \%$, alkohol 90\%, alkohol 96\%, toluene 1 dan toluene 2 masing-masing selama dua jam. Selanjutnya jaringan dimasukkan ke dalam paraffin cair $56^{\circ} \mathrm{C}$ selama dua jam sebanyak dua kali. Jaringan kemudian diambil dengan pinset, dilanjutkan pemblokan menggunaka paraffin blok. Tahap selanjutnya dilakukan pemotongan (cutting) menggunakan mikrotom dengan ketebalan 4-5 $\mu \mathrm{m}$. Jaringan yang telah dipotong dikembangkan di atas air dalam penangas air (waterbath), kemudian ditangkap dengan gelas objek.

Prosedur pewarnaan HE mengacu pada metode Kiernan (2010). Proses pewarnaan diawali dengan proses deparafinisasi atau penghilangan parafin dengan menggunakan xylol sebanyak tiga kali pengulangan, masing-masing selama dua menit, dilanjutkan dengan pemasukan kembali air ke dalam jaringan (rehidrasi) dengan menggunakan larutan alkohol dengan konsentrasi menurun (absolut, $95 \%, 90 \%$, 80\%, dan 70\%), masingmasing selama lima menit. Kemudian dilakukan pembilasan dengan air mengalir selama 10 menit diikuti pembilasan dengan menggunakan akuades selama 10 menit. Selanjutnya jaringan diwarnai dengan pewarnaan hematoksilin selama dua menit (sambil dikontrol di bawah mikroskop cahaya) dan dibilas kembali dengan menggunakan air mengalir. Lalu jaringan diwarnai dengan pewarnaan eosin selama dua menit (sambil dikontrol di bawah mikroskop cahaya) dan diikuti proses dehidrasi dengan menggunakan larutan alkohol bertingkat. Proses penjernihan (clearing) dengan xylol, dan diakhiri penutupan jaringan dengan kaca penutup (proses mounting) dengan menggunakan bahan perekat Entellan.

\section{Pengamatan preparat histologi}

Struktur histologi ginjal diamati menggunakan mikroskop cahaya dengan pembesaran lensa objektif 50, 200, 1000.

\section{Pengukuran histomorfometri}

Pengukuran dilakukan dibawah mikroskop dengan menggunakan pembesaran lensa objektif 50, 200, 1000 menggunakan calzeiss teaching microscope. Variabel yang diukur adalah tebal kapsula, kortek, dan medula serta luas glomerulus.

\section{Cara pengumpulan data}

Data yang dikumpulkan yaitu dari hasil pengamatan anatomi dan histologi organ ginjal anjing kintamani. Data anatomi meliputi ketebalan kortek, medula, pelvis, dan berat dari ginjal. Data histologi diperoleh dari hasil pengamatan struktur histologi kapsula, kortek dan medula sedangkan histomorfometri dari hasil pengukuran kapsula, kortek, medula dan glomerulus.

\section{Analisis data}

Data yang diperoleh kemudian dianalisis dengan independent samples $T$ test dengan bantuan piranti sofware SPSS. Hasil pengamatan dari struktur anatomi dan histologi dianalisis secara deskriptif kualitatif, sedangkan hasil pengukuran panjang, lebar, dan tebal secara deskriptif kuantitatif.

\section{HASIL DAN PEMBAHASAN}

\section{Morfologi}

Hasil pengamtan morfologi yang dilakukan pada ginjal anjing kintamani betina secara anatomi didapatkan hasil bahwa letak ginjal kanan anjing kintamani berada diantara os vertebrae lumbal 1-3 dan ginjal kiri terletak dibawah os vertebrae lumbal 2-4. Bentuk ginjal anjing kintamani seperti kacang merah, memiliki permukaan halus dan berwarna merah kecoklatan dimana ginjal kiri sedikit lebih panjang dari ginjal kanan (Gambar 1). Ginjal anjing kintamnai terdiri dari tiga bagian yaitu kortek yang memiliki warana 
merah kecoklatan, medula berwarna lebih cerah dari kortek dikarenakan banyak terdapat pembuluh darah, dan pelvis

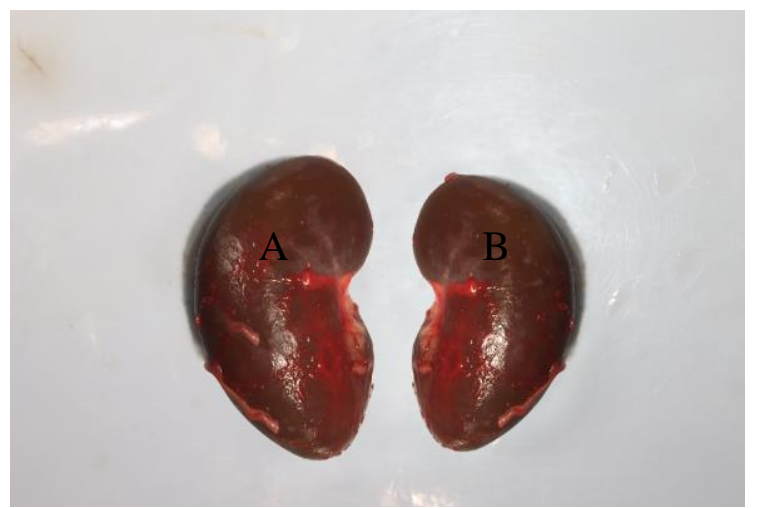

Gambar 1. Ginjal

Keterangan: (A): Ginjal kiri; (B): Ginjal kanan.

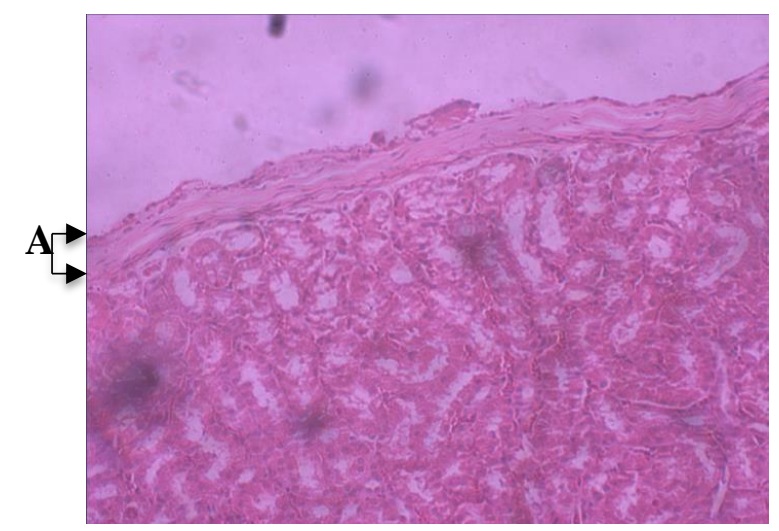

Gambar 3. Kapsula (HE) (200x)

Keterangan: (A): Bagian kapsula

Hasil pengamatan morfologi yang dilakukan pada anjing kintamani betina secara histologi didapatkan bahwa ginjal terdiri dari kapsula, kortek, dan medulla (Gambar 3 dan 4). Dimana kapsula yang membalut ginjal memiliki serabut kolagen serta serabut elastik pekat, serta bagian dalam terdiri dari jaringan ikat longgar, dan fibroblast (Gambar 3). Sedangkan kortek tersusun dari epitel-epitel kuboid. Didalam kortek terdapat banyak glomerulus dan kapsula bowman yang mengelilingi setiap glomerulus serta podosit yang menyusun glomerulus (Gambar 7) dan juga di bagian kortek terdapat tubulus proximal dan tubulus memiliki warna bening kekuningan yang dikarenakan pelvis tersusun oleh banyak jaringan ikat (Gambar 2).

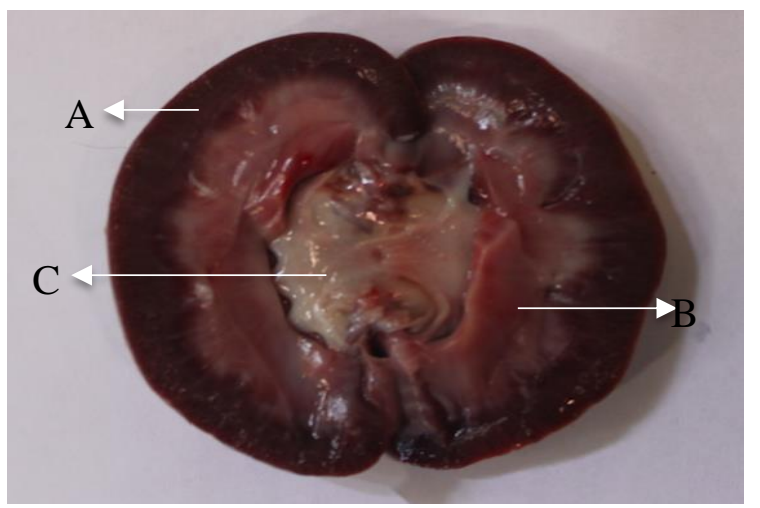

Gambar 2. Struktur anatomi ginjal Keterangan: (A): Kortek; (B): Medula; (C): Pelvis.

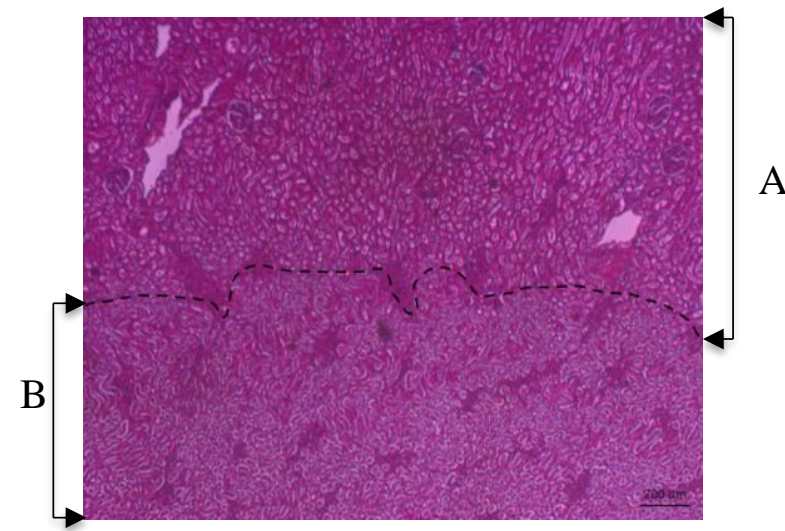

Gambar 4. Struktur histologi ginjal (HE) (50x), Keteranga: (A): Kortek (B): Medula

distal (Gambar 6) Medula tersusun dari epitel-epitel kuboid simplek, tubulus kolektivus, dan loop henle (Gambar 8).

\section{Morfometri}

Dari hasil analisis T-test pada Tabel 1 menunjukkan bahwa berat ginjal kanan berbeda nyata $(\mathrm{P}<0,05)$ dengan berat ginjal kiri, sedangkan panjang ginjal kanan, lebar ginjal kanan, ketebalan kortek ginjal kanan, ketebal medula ginjal kanan, ketebal dan pelvis ginjal kanan tidak berbeda nyata $(\mathrm{P}>0,05)$ dengan panjang ginjal kiri, lebar ginjal kiri, ketebalan kortek ginjal kiri, ketebal medula ginjal kiri, ketebalan pelvis ginjal kiri. 


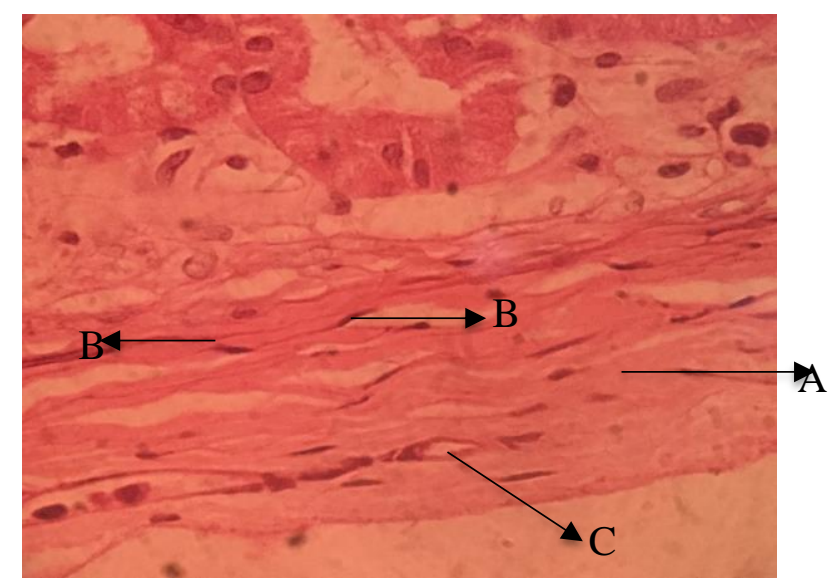

Gambar 5. Kapsula (HE) (1000x)

Keterangan: (A): Jaringan ikat; (B):

Fibroblast; (C): Vaso darah.

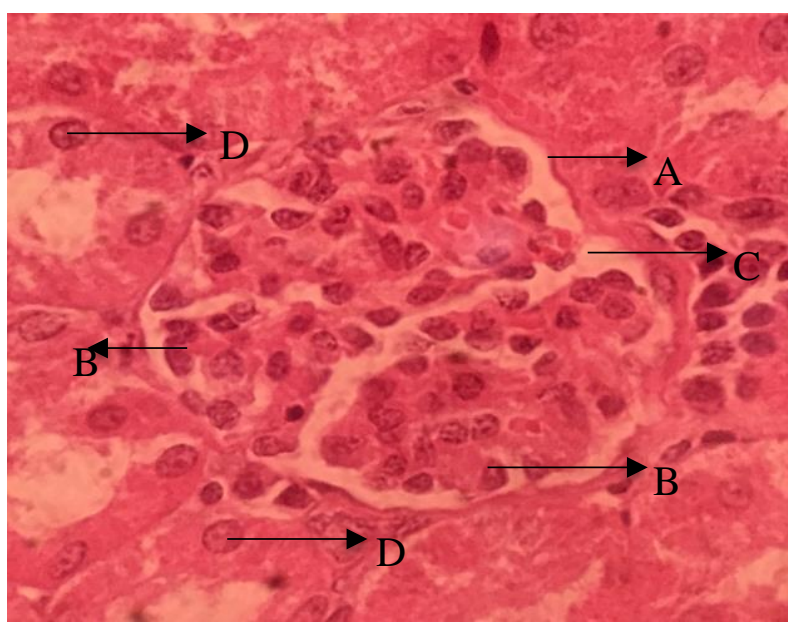

Gambar 7. Glomerulus (HE) (1000x)

Keterangan: (A): Kapsula bowman; (B):

Podosit; (C): Urinary space; (D): Epitel kuboid simplek.

\section{Histomorfometri}

Berdasarkan hasil pengukuran histomorfometri bahwa rata-rata ketebalan kapsula pada anjing kintamani betina adalah $37,18 \pm 5,67 \mu \mathrm{m}$, ketebalan kortek 3.798,34 $\pm 603,54 \mu \mathrm{m}$, ketebalan medula $1.485,09 \pm 286,92 \mu \mathrm{m}$, dan luas rata-rata glomerulus pada ginjal anjing kintamani betina adalah 8.598,34 $\pm 1.277,06 \mu \mathrm{m}$ (Tabel 2).

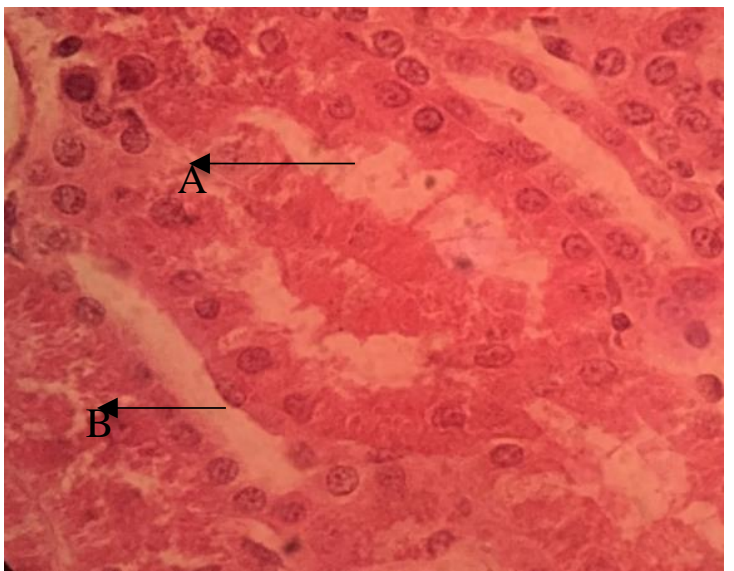

Gambar 6. Kortek (HE) (1000x)

Keterangan: (A): Tubulus proximal;

(B): Tubulus distal.

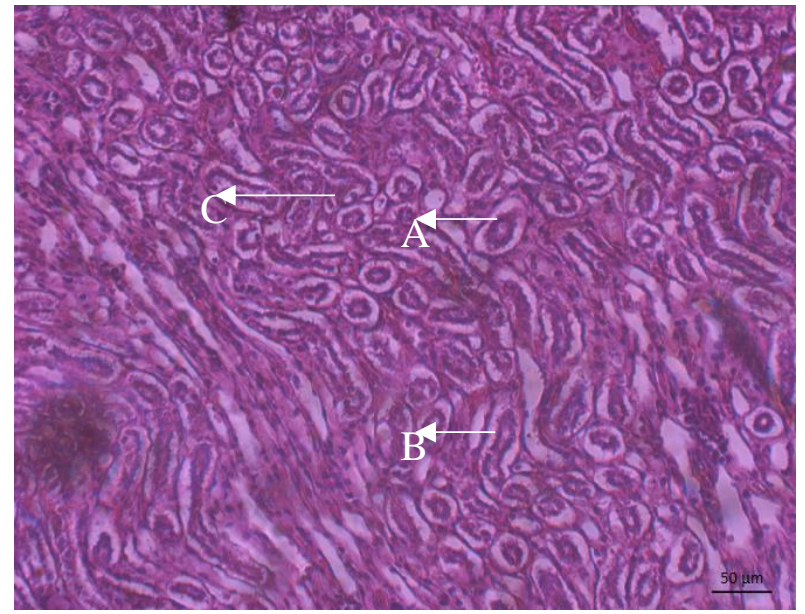

Gambar 8. Medula (HE) (200x)

Keterangan: (A): Tubulus kolektivus;

(B): Tubulus kolektivus; (C): Loop henle.

\section{Morfologi}

Berdasarkan hasil morfologi anatomi diatas bentuk dari ginjal anjing kintamani betina sama dengan bentuk ginjal anjing yang dilaporkan oleh Bloom (1954), seperti buah buncis atau kacang merah, lebih panjang, lebih tipis dibandingkan dengan ginjal kucing itu disebabkan karena perbedaan spesies. Evan (1993), mengatakan letak dari ginjal kanan anjing yaitu terletak pada bagian ventral sampai 
bagian dorsal dari dua atau tiga tulang rusuk terakhir dan prosesesus transversal lumbar pertama. Ginjal kiri biasanya terletak pada bagian ventral tulang rusuk terakhir dan dua atau tiga prosesus transversus lumbar pertama. Sedangkan menurut Bloom (1954) ginjal kanan terletak diantara os vertebrae lumbal satu sampai tiga dan ginjal kiri lebih ke kaudal terletak dibawah os vertebrae lumbal dua sampai empat. (Bloom, 1945) dan (Dellman dan Brown, 1987).

Berdasarkan hasil diatas morfologi histologi ginjal anjing kintamani betina terdiri dari bagian luar yaitu kapsula yang membalut ginjal dan memiliki serabut kolagen, serabut elastik pekat, fibroblast, vaso darah serta bagian dalam terdiri dari jaringan ikat longgar, sehingga pada anjing kuda dan babi tampak adanya otot polos (Dellman dan Brown, 1987). Susunan selanjutnya adalah bagian kortek, Epitelepitel yang terdapat dalam bagian kortek anjing kintamani adalah epitel kuboid simplek dan juga terdapat tubulus distal serta tubulus proximal. Pada bagian kortek juga terdapat glomerulus dimana glomerulus dikelilingi oleh kapsul glomerulus (kapsula bowman) dimana lapisan visceral dari ginjal tersebut terbentuk oleh podosit yang menutupi kapiler glomerulus dan lapisan parietal yang terbentuk dari epitel skuamosa. Diantara 2 lapisan katung kemih terdapat filtrasi barrier (Baragoth et al., 2014). Medula tampak lebih cerah dari pada kortek, epitel yang terdapat pada bagian medula adalah epitel kuboid simplek serta terdapat tubulus kolektivus dan loop henle. Tampak adanya jalur-jalur yang disebabkan oleh buluh-buluh kemih yang lurus dan pembuluh darahnya (Dellman dan Brown, 1987).

\section{Morfometri}

Berdasarkan hasil pengukuran berat ginjal anjing kintamni betina adalah ratarata 19,39 \pm 4,24 g untuk ginjal bagian kanan sedangkan ginjal bagian kiri adalah $20,51 \pm 4,20 \mathrm{~g}$ sangat berbeda jauh dengan berat ginjal pada anjing yang dilaporakn oleh Rishikesh et al., (2018) yaitu berat ginjal kanan adalah 38,64 \pm 17,2 g dan ginjal kiri 38,86 $\pm 19,50$ g. Sedangkan untuk hasil pengukuran panjang ginjal pada anjing kintamani betina adalah ginjal kanan rata-rata $50,19 \pm 2,43 \mathrm{~mm}$ dan panjang ginjal kiri adalah 50,88 $\pm 2,38 \mathrm{~mm}$ juga berbeda dengan panjang ginjal pada anjing yang dilaporkan oleh Rishikesh et al., (2018) yaitu panjang ginjal kanan adalah 5,87 $\pm 0,97 \mathrm{~cm}(58,7 \mathrm{~mm})$ dan panjang ginjal kiri adalah $5,95 \pm 0.98 \mathrm{~cm}$ $(59,5 \mathrm{~mm})$. Untuk hasil pengukuran lebar dari ginjal anjing kintamani betina adalah rata-rata ginjal kanan 29,57 $\pm 1,94 \mathrm{~mm}$ dan lebar ginjal kiri adalah 29,40 $\pm 1,65 \mathrm{~mm}$ sedangkan lebar ginjal kanan pada anjing yang dilaporkan oleh Rishikesh et al (2018) adalah 3,01 $\pm 0,42 \mathrm{~cm}(30,1 \mathrm{~mm})$ dan lebar ginjal kiri adalah $3,40 \pm 0,47 \mathrm{~cm}$ $(34,0 \mathrm{~mm})$. Perbedaan diatas dapat dikarenakan perbedaan ras anjing.

Tabel 1. Rata-rata Panjang dan lebar ginjal, dan ketebalan kortek, medula, dan pelvis Anjing Kintamani betina

\begin{tabular}{lcc}
\hline \multirow{2}{*}{\multicolumn{1}{c}{ Organ }} & \multicolumn{2}{c}{ Rata-rata \pm Standar Deviasi } \\
\cline { 2 - 3 } & Kanan & Kiri \\
\hline Berat ginjal $(\mathrm{g})$ & $19,39 \pm 4,24^{\mathrm{a}}$ & $20,51 \pm 4,20^{\mathrm{b}}$ \\
Panjang ginjal $(\mathrm{mm})$ & $50,19 \pm 2,43^{\mathrm{a}}$ & $50,88 \pm 2,38^{\mathrm{a}}$ \\
Lebar ginjal $(\mathrm{mm})$ & $29,57 \pm 1,94^{\mathrm{a}}$ & $29,40 \pm 1,65^{\mathrm{a}}$ \\
Ketebalan kortek $(\mathrm{mm})$ & $6,17 \pm 0,45^{\mathrm{a}}$ & $6,17 \pm 0,31^{\mathrm{a}}$ \\
Ketebalan medulla $(\mathrm{mm})$ & $8,48 \pm 0,56^{\mathrm{a}}$ & $8,50 \pm 0,49^{\mathrm{a}}$ \\
Ketebalan pelvis $(\mathrm{mm})$ & $8,11 \pm 1,29^{\mathrm{a}}$ & $8,95 \pm 2,08^{\mathrm{a}}$
\end{tabular}

Keterangan: Huruf yang berbeda pada baris yang sama menunjukkan berbeda nyata $(\mathrm{P}<0,05)$ 
Tabel 2. Rata-rata Ketebalan kapsula, ketebalan kortek, ketebalan medulla, dan luar glomerulus

\begin{tabular}{cc}
\hline Parameter & Rata-rata \pm Standar Deviasi \\
\hline Ketebalan kapsula $(\mu \mathrm{m})$ & $37,18 \pm 5,67$ \\
Keteblan kortek $(\mu \mathrm{m})$ & $3.798,34 \pm 603,54$ \\
Ketebalan medula $(\mu \mathrm{m})$ & $1.485,09 \pm 286,92$ \\
Luas glomerulus $(\mu \mathrm{m})$ & $8.598,34 \pm 1.277,06$
\end{tabular}

\section{SIMPULAN DAN SARAN}

\section{Simpulan}

Ginjal anjing kintamani betina secara makroskopik berbentuk seperti buah buncis atau kacang merah dan morfologinya tersusun dari kortek, medula, dan pelvis sedangkan morfometrinya yakni berat ginjal kanan dan kiri berturut-turut 19,39 \pm 4,24 g dan 20,51 $\pm 4,20 \mathrm{~g}$, panjang ginjal kanan dan kiri $50,19 \pm 2,43 \mathrm{~mm}$ dan $50,88 \pm 2,38$ $\mathrm{mm}$, lebar ginjal kanan dan kiri 29,57 \pm

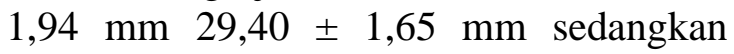
untuk ketebalan kortek kanan dan kiri 6,17 $\pm 0,45$ dan $6,17 \pm 0,31 \mathrm{~mm}$, ketebalan medula kanan dan kiri 8,48 $\pm 0,56 \mathrm{~mm}$ dan $8,50 \pm 0,49 \mathrm{~mm}$, ketebalan pelvis kanan dan kiri 8,11 $\pm 1,29$ dan 8,95 $\pm 2,08 \mathrm{~mm}$.

Ginjal anjing kintamani betina secara mikroskpik struktur mofologinya tersusun dari kapsula, kortek, medula, pelvis, glomerulus, tubulus distal, tubulus proximal, tubulus kolektivus, pembuluh darah, loop henle. epitel-epitel kuboid, dan podosit yang menyusun glomerulus. Sedangkan histomorfometri yakni tebal kapsula 37,18 $\pm 5,67 \mu \mathrm{m}$, tebal kortek $3.798,34 \pm 603,54 \mu \mathrm{m}$, tebal medula $1.485,09 \pm 286,92 \mu \mathrm{m}$ dan luas glomerulus $8.598,34 \pm 1.277,06 \mu \mathrm{m}$.

\section{Saran}

Perlu adanya penelitian lebih lanjut mengenai morfologi dan morfometri dari ginjal anjing kintamani jantan, Penelitian anjing kinamani berdasarkan kelompok umur, dan penelitian anjing kintamani berdasarkan status kesehatan.

\section{UCAPAN TERIMAKASIH}

Penulis mengucapkan terimakasih kepada Dekan Fakultas Kedokteran Hewan Universitas Udayana yang telah memfasilitasi pelaksanaan penelitian ini.

\section{DAFTAR PUSTAKA}

Bloom F. 1954. Pathology of the dog and cat. American Veterinary Publication, Evanston, Illinois.

Dellman HD, Brown EM. 1987. Textbook of Veterinary Histology. Lea \& Febiger.

Dimitrov R, Kostov D, Stamatova K, Yordanova $\quad$ V. 2012. Anatomotopographical and Morphological Analysis of Normal Kidney of Rabbit (Oryctolagus Cuniculus). Trakia J. Sci., 10(2): 7984.

Evans HD. 1993. Anatomy of The Dog. $3^{\text {rd }}$ ed. Library of Congress Cataloging-inPublication Data. Pp. 458-460.

Luna LG. 1968. Manual Histologic Staining Methods of Pathology. $3^{\text {rd }} \mathrm{Ed}$. The Blakiston Division Mc Graw-hill Book Company, New York, Toronto, London, Sydney.

Puja IK, Irion DN, Schaffer AL, Pedersen NC. 2005. The Kintamni Dog: Genetic profil of an emerging breed from Bali, Indonesia. J. Heredity, 96(7): 854-859.

Puja IK. 2007. Anjing Kintamani Bali Maskot Fauna Kabupaten Bangli. Universitas Udayana. Denpasar.

Ramdhany DN, Kustiyo A, Handharyani E, Buono A. 2009. Diagnosa Gangguan Sistem Urinari Pada Anjing dan Kucing Menggunakan VFI 5. J. Ilmu Komp. dan Inform., 2(2): 86-94. 
Rishikesh M, Kirath K, Punit K. 2018. Anatomical and physiological similari es of kidney in di erent experimental animals. J. Clin. Experimental Nephrol., 3(2): 1-6.
Yanuartono, Nururrozi A, Indarjulianto S. 2017. Penyakit ginjal kronis pada anjing dan kucing: manajemen terapi dan diet. J. Sains Vet., 35(1): 16-34. 